\title{
LA TEORÍA DISCURSIVA DEL DERECHO DE JÜRGEN HABERMAS COMO PARADIGMA PARA LA CIENCIA DEL DERECHO
}

\author{
José María Carabante MunTADA \\ Profesor de Filosofía del Derecho \\ en el Centro Universitario Villanueva. UCM. \\ jcarabante@villanueva.edu
}

\begin{abstract}
RESUMEN
En este artículo se analiza la teoría discursiva del Derecho de J. Habermas desde el punto de vista de la ciencia jurídica. Se trata de comprobar sus bases epistemológicas y metodológicas y ensayar si la propuesta habermasiana puede ser una alternativa a los planteamientos existentes. De esa forma, la Teoría del Derecho se actualizaría y podría aclarar su propio estatuto científico, justo en el momento en que se han cambiado aspectos sustantivos y docentes con motivo de la adaptación de la materia a los nuevos planes de estudio.

Palabras clave: Teoría del Derecho, ciencia jurídica, Jürgen Habermas, Teoría de la Sociedad.

\section{ABSTRACT}

This article examines J. Habermas' discourse theory of Law from the perspective of legal science. This involves substantiating the epistemological and methodological basis and to test whether the Habermasian proposal could serve as an alternative to existing approaches. Thus, the Theory of Law would be updated and its own scientific statute could be clarified, just at a time when the substantive and teaching aspects for the purpose of adapting the material to the new curriculum bave been changed.
\end{abstract}

Keywords: Theory of Law, Legal Science, Jürgen Habermas, Theory of Society.

\section{ZUSAMMENFASSUNG}

Dieser Artikel untersucht die diskursive Rechtstheorie von J. Habermas aus Sicht der Rechtswissenschaft. Es gebt darum, die erkenntnistheoretischen und methodologischen Grundlagen zu überprüfen sowie zu testen, ob der Habermassche Vorschlag eine Alternative zu den existierenden Entwürfen darstellt. Dadurch könnte sich die Rechtstheorie aktualisieren und ibre eigenen wissenschaftlichen Satzungen zu einem Zeitpunkt darlegen, an welchem substantielle und die Lebre betreffende Aspekte aufgrund der Anpassung der Inhalte an die neuen Studienrabmenrichtlinien verändert wurden.

Schlüsselwörter: Rechtstheorie, Rechtswissenschaft, Jürgen Habermas, Gesellschaftstheorie. 
SUMARIO: I. INTRODUCCIÓN.-II. DE LA TEORÍA DE LA SOCIEDAD AL DERECHO.-III. LA DUALIDAD INMANENTE DE LA TEORÍA DISCURSIVA DEL DERECHO.-IV. DIMENSIONES SOCIOLÓGICAS Y FILOSÓFICAS. EL DERECHO MODERNO COMO GARANTÍA DEL ORDEN SOCIAL.-V. EL DERECHO, ENTRE LA POLÍTICA Y LA MORAL.-VI. CONCLUSIONES.

\section{INTRODUCCIÓN}

Podría parecer que los nuevos planes de estudios que han entrado en vigor como consecuencia de la implantación del Espacio Europeo de Educación Superior, apenas reflejan cambios mínimos en las tradicionales asignaturas de la licenciatura de Derecho. En este sentido, desde que diversas modificaciones legales transformaron la enseñanza universitaria, la asignatura de Teoría del Derecho ha estado siempre presente, de alguna u otra manera, en cada una de las renovaciones curriculares. Y, ciertamente, la historia de la propia Teoría del Derecho es larga ${ }^{1}$. Tal vez por ello, es decir, quizá porque la consolidación científica de la Teoría del Derecho es un fait accompli, la reflexión epistemológica acerca de su propio estatuto, su función y virtualidad haya sido postergada por la necesidad de ampliar su propia temática y de reflejar en su exposición cambios pedagógicos o sustantivos más bien superficiales. En otras palabras, se ha prestado más atención al contenido, a la materia de la disciplina, que a su estatuto trascendental ${ }^{2}$. No es de extrañar que, debido a ello, hayan proliferado los manuales y exposiciones sistemáticas sobre la Teoría del Derecho, que habría de tratar, como se sostiene canónicamente, de una temática concreta. Pero lo cierto es que se ha generalizado en la disciplina cierta alergia a las fundamentaciones epistemológicas y a las posibilidades científicas de la misma, dando por supuesto, en general, el objeto del que se ocupa y obviando su fundamentación.

Si se tiene en cuenta que el surgimiento de la Teoría del Derecho coincidió con el predominio de una mentalidad histórica, que hermanaba e incluso identificaba conocimiento y ciencia, no puede pasarse por alto ni deben menospreciarse los cambios acaecidos en el campo de la epistemología. Por tanto, con independencia de que entre los especialistas en filo-

${ }^{1}$ Puede verse, por ejemplo, el estudio de K. Larenz, Metodología de la Ciencia del Derecho, Madrid, 2001.

${ }^{2}$ Nos referimos a trascendental en sentido kantiano, pero sin menospreciar los cambios acaecidos en la conciencia científica de tipo postempirista. 
sofía y teoría jurídica estén claros los contenidos docentes a impartir, es menester revisar y profundizar sobre los fundamentos gnoseológicos de la ciencia del Derecho. No estaría de más, por ejemplo, recurrir a las instrumentaciones de carácter gnoseológico que han aparecido al cabo del tiempo en otras disciplinas afines, especialmente las relacionadas con el ámbito de las ciencias sociales, para ponderar de esa forma sus consecuencias en el propio campo de la ciencia jurídica. Sólo de esta manera podrán hacerse realidad algunos de las pretensiones que constituyen la razón de ser del Espacio Europeo de Educación Superior.

En este sentido, uno de los planteamientos más innovadores en las ciencias sociales es el realizado por el pensador alemán Jürgen Habermas. Aunque su aportación principal es la de configurar una nueva Teoría de la Sociedad que sintetice, desde un punto de vista metodológico, la perspectiva descriptiva de las ciencias - de las nuevas ciencias - con el enfoque normativo propio de la Filosofía, precisamente el interés de fundar en la razón sus propios constructos teóricos hacen de su obra un lugar apropiado para comprobar la fiabilidad científica de una nueva Teoría del Derecho. Habermas no ha renunciado, pues, a buscar —ni a ensayar, por cierto- una nueva fundamentación para las ciencias sociales que se opone a otro tipo de planteamientos antifundacionalistas y posmodernos, así como a sus conclusiones prácticas ${ }^{3}$.

Se ha reflexionado sobre la propuesta social habermasiana en incontables ocasiones. También hay estudios expositivos sobre su teoría discursiva que han reparado en la fundamentación metodológica que realiza, pero no se han propuesto sus bases para actualizar la Teoría del Derecho contemporánea sobre su paradigma ${ }^{4}$. Es precisamente llenar este hueco lo que pretendemos hacer nosotros. Porque la teoría deliberativa o discursiva del Derecho, que nace de la Teoría de la Sociedad habermasiana, constituye una alternativa a los paradigmas jurídicos actuales fundada científicamente. Así, en estudios panorámicos sobre la Filosofía y la teoría jurídica contemporánea post-empirista se llama la atención sobre la dualidad entre la apertura de la disciplina a los valores ético-políticos, de un lado, y

\footnotetext{
${ }^{3}$ Así serían las aproximaciones de R. Rorty, por ejemplo, o Derrida. Habermas se ha enfrentado también a las aporías de la posmodernidad en J. HABERMAS, El discurso filosófico de la modernidad, Madrid, 1989.

${ }^{4}$ Cfr. J. C. Velasco, La Teoría discursiva del Derecho. Sistema jurídico y democracia en Habermas, Madrid, 2000. R. Alexy ha continuado algunas de las intuiciones habermasianas, desarrollando una teoría propia. Cfr. R. Alexy, Teoría de la argumentación jurídica, Madrid, 1989.
} 
al mundo de los hechos, por otro. Habermas, como veremos, intenta combinar ambos enfoques 5 .

La teoría habermasiana del Derecho se nos presenta, pues, como un proyecto integrador y con un alcance especulativo suficiente para poner fin, o al menos aparcar, la tradicional confrontación entre ciencia jurídica y filosofía del Derecho ${ }^{6}$. Para explicar estos extremos es necesario hacer una mención, aunque breve y con fines aclaratorios, a la pragmática universal, verdadero paradigma epistemológico y metodológico de la ciencia del Derecho.

\section{DE LA TEORÍA DE LA SOCIEDAD AL DERECHO}

La preocupación de Jürgen Habermas por el Derecho es una constante en su obra en la que se encuentran con frecuencia reflexiones teórico-jurídicas. Desde su tesis de habilitación, publicada en 1962 y que estaba dedicada a analizar los cambios de la esfera pública burguesa - con efectos también en el ámbito jurídico-, pasando por Theorie und praxis, donde se ocupa de las decantaciones del iusnaturalismo racionalista, hasta el planteamiento de la legitimidad de las normas que aparece en Problemas de legitimación en el capitalismo tardio, toda la trayectoria de Habermas se encuentra jalonada de referencias más o menos implícitas a problemas iusfilosóficos. Sin menospreciar los pasos que da en las obras mencionadas, sólo puede hablarse de una Teoría del Derecho habermasiana a raíz de la publicación, en los años noventa, de Faktizität und Geltung, porque es en ese ensayo cuando de forma sistemática y científica se ocupa del Derecho, en concreto de la validez científica y normativa de una teoría jurídica deliberativa o discursiva. El grueso de esa obra está dedicado a reconstruir, con el telón de fondo de la acción comunicativa, el sistema moderno de derechos y el nacimiento del Estado de Derecho, así como a proponer un nuevo paradigma jurídico sobre las bases de la pragmática universal. Ahî es cuando el Derecho adquiere una mayor relevancia en la trayectoria de Habermas, ya que concluye que la teoría jurídica constituye una exigencia interna de su Teoría de la Sociedad, porque, de otro modo, su propuesta sociológica quedaría incompleta. Cierto es, sin embargo, que tiene que

5 Vid. C. Faralli, La filosofía del Derecho contemporánea, Madrid, 2007, p. 16. Aunque la profesora Faralli incluye la propuesta de Habermas en la primera línea de estudio, lo hace en referencia a aspectos materiales de su teoría discursiva. Cfr. para ello pp. 94 ss.

${ }^{6}$ Cfr. M. Rodríguez Molinero, Introducción a la Filosofía del Derecho, Madrid, 2006, pp. 63 ss. 
pasar por alto algunos problemas específicos para que adquiera coherencia su proyecto social omnicomprensivo.

Pero si simplemente tuviéramos en cuenta esto no podría justificarse la novedad epistemológica de la Teoría habermasiana del Derecho: exclusivamente nos habríamos referido a su proposición como una exigencia más que plantea la coherencia sistémica de un planteamiento científico. Tampoco serviría para explicar su Teoría discursiva del Derecho la necesidad de apuntalar coactivamente un planteamiento moral que no encuentra motivación suficiente para que los ciudadanos adecuen su conducta a él. En uno y otro caso, la propuesta habermasiana sería, sin lugar a dudas, relevante, pero no podría recurrirse a ella para ensanchar un horizonte teórico como el representado en la actualidad por la Teoría del Derecho.

A nuestro juicio, sería un grave error entender que Theorie des kommunikativen Handelns es sólo un trabajo sociológico; más allá de ello, es una de las obras fundamentales para entender la filosofía social y también jurídica del siglo Xx. Sus pretensiones continúan la necesidad de recuperar y radicalizar el proyecto de la modernidad, superando sus insuficiencias cientificistas y decisionistas. Consciente de la imposibilidad de reivindicaciones ontológicas y sabedor del carácter falibista que ha tomado la ciencia contemporánea, Habermas busca ensanchar los límites de la racionalidad y resituar la razón en la práctica comunicativa de los hablantes, vinculando sociología y análisis de la razón ${ }^{7}$. De esa forma, la ciencia social toma el testigo de la filosofía y se presenta como la única disciplina capaz de plantear con suficiencia la cuestión de la racionalidad y en su caso responderla ${ }^{8}$. Pero si la filosofía, tal y como estaba planteada, capitula ante las ciencias sociales, es lógico pensar que también una reflexión filosófica más específica como la que realiza la filosofía jurídica ha de correr la misma suerte.

Resulta oportuno, a los efectos de reflexionar sobre esta Teoría del Derecho, realizar un repaso, aunque sucinto, de la fundamentación de la ciencia social que lleva a cabo Habermas en su Teoría de la acción comunicativa. La aceptación de su planteamiento teórico-jurídico depende de ella en la medida en que descubre y explica una nueva noción de racionalidad que transforma —o, al menos, debiera hacerlo— la raíz epistemológica y gnoseológica de las ciencias sociales y, por tanto, afecta necesariamen-

${ }^{7}$ Para un recorrido por la obra de Habermas sigue siendo indispensable, pese a no incluir un análisis de la acción comunicativa, el clásico de Th. MACCARTHY, The critical theory of Jürgen Habermas, Cambridge, 1984. Asimismo, se puede consultar S. K. White (ed.), The Cambridge companion to Habermas, Cambridge, 1995.

${ }^{8}$ Cfr. J. Habermas, Teoría de la acción comunicativa, vol. I., Madrid, 1987, p. 16. 
te al Derecho por varios motivos. En primer término, en el contexto del pensamiento postmetafísico, la intención más radical a la que puede aspirar la Filosofía consiste en indagar los problemas de racionalidad y vigilar el cumplimiento de sus criterios en los ámbitos científicos concretos, toda vez que los intentos de fundamentación última han terminado en fracasos estrepitosos. De ahí que, en segundo lugar, una ampliación del modelo de razón sólo sea posible en un sentido formal y no sustantivista, pues ha de permitir entrelazar las explicaciones sobre las condiciones procedimentales de la racionalidad con análisis empíricos. Como veremos, este modelo es el ofrecido, según Habermas, por las llamadas ciencias reconstructivas. En tercer término, a partir de las contribuciones de la filosofía del lenguaje no puede separarse la investigación sobre la racionalidad de las condiciones sociales del surgimiento y uso de la capacidad lingüística. En conclusión, el interrogante inicial sobre las condiciones de la racionalidad conduce inexorablemente a un análisis social de las estructuras lingüísticas.

De esa forma, la ciencia que hoy día piensa los problemas de la racionalidad es la Sociología, tanto por motivos metateóricos, como metodológicos y sustantivos. En efecto, esta disciplina categoriza el desarrollo social en términos de racionalidad de la acción y, al tiempo, aborda el problema de la comprensión del sentido de las acciones individuales y colectivas, sin olvidar las cuestiones empíricas y la comprobación macrosociológica de sus intuiciones teóricas. Así, la Teoría de la Sociedad de Habermas se postula como una ciencia reconstructiva que, sin renunciar a su cientificidad, se concibe normativamente, teniendo en cuenta, sin embargo, que estas pretensiones teóricas tienen que acreditarse empíricamente.

En relación con su concepción jurídica, debemos resaltar que lo que con posterioridad se ha conocido como Teoría deliberativa del Derecho supone, a fin de cuentas, una aplicación práctica de los postulados fundamentales de la racionalidad discursiva que Habermas diseña como base última de su Teoría de la Sociedad. Como indicábamos, si la base de la misma ha de contener dos momentos imprescindibles - normativo y empírico- - la tensión constructiva entre la validez y su facticidad, se revela la idoneidad de la pragmática para tratar el aspecto clave del fenómeno jurídico. En cualquier caso, es menester aclarar qué entiende Habermas por pragmática universal, su proyecto teórico más ambicioso.

La pragmática tiene por objeto la reconstrucción del saber implícito de los hablantes que se manifiesta en reglas. En un conocido texto, ¿Qué significa pragmática universal?, el pensador alemán reconoce que encontró inspiración en las investigaciones semióticas de K. O. Apel y en la transfor- 
mación lingüística de la filosofía trascendental kantiana ${ }^{9}$. A partir de estos presupuestos, el punto de vista pragmático es especialmente interesante para las ciencias prácticas, porque privilegia la inserción de la razón en la praxis social del hombre ${ }^{10}$. La pragmática busca analizar el acto de comunicación o acto de habla entre hablante y oyente, dando por supuesto que los participantes en las interacciones comunicativas poseen una competencia específica ${ }^{11}$. Esta perspectiva se conforma al canon epistemológico de las ciencias reconstructivas, con un alto potencial explicativo, porque su fin es identificar las condiciones universales del entendimiento posible, esto es, detectar los presupuestos universales que han de darse para que tenga lugar la comunicación y entendimiento ${ }^{12}$.

No hay duda de que el punto de vista pragmático es muy relevante para la Teoría del Derecho porque la pragmática «considera el lenguaje de una forma dinámica [...] como un conjunto de situaciones comunicativas» ${ }^{13}$, y siguiendo la propuesta habermasiana se han desarrollado aportaciones en el ámbito jurídico. Para nuestros fines, más epistemológicos que sustantivos, es importante advertir que con la reivindicación del punto de vista pragmático Habermas se sitúa en el centro de los debates filosóficos y sociológicos más relevantes de la actualidad, ya que la pragmática es, precisamente, la rama de mayor interés tanto en la filosofía del lenguaje como en otras disciplinas ${ }^{14}$.

La pragmática, en el caso de Habermas, se postula como una especie de ciencia última, como una forma contingente de fundamentación, como una perentoria y urgente sustitución de la ontología. Y si el pensamiento postmetafísico no puede recurrir por razones de principios a sustancias fundantes, la pragmática ha de ser formal sin abandonar por ello su vinculación con tareas normativas. Una pragmática meramente empírica no dispondría de los instrumentos conceptuales necesarios para descubrir los

\footnotetext{
9 Cfr. K. O. Apel, La transformación de la Filosofía, vol. II, Madrid, 1987, p. 155.

${ }^{10}$ Ibid., p. 170. La influencia del pragmatismo americano, especialmente de Peirce, es visible también en Habermas; cfr. J. Habermas, Conocimiento e interés, Madrid, 1982, pp. 97 ss.

${ }_{11}$ Véase en este aspecto su trabajo «Notas sobre el desarrollo de la competencia interactiva» (1974), en Teoría de la acción comunicativa. Complementos y estudios previos, Madrid, 1989, pp. 161 ss.

12 Ibid., pp. 279 y 299. Una defensa del paradigma representado por las ciencias reconstructivas la ofrece Habermas en Conciencia moral y acción comunicativa, Madrid, 2008, pp. 42 ss.

${ }_{13}$ Vid. J. J. Acero, E. Bustos y D. Quesada, Introducción a la filosofía del lenguaje, Madrid, 2010, p. 28.

${ }^{14}$ Ibid., p. 28.
} 
fundamentos racionales de la comunicación insertos en la confusión y en la distorsión de las prácticas cotidianas, y escaparía al vuelo de la crítica ${ }^{15}$. Lo relevante, en cualquier caso, es que en el análisis del proceso de comunicación es fácil percatarse de que lo que emisor y receptor pretenden es entenderse o, lo que es lo mismo, iniciar «un proceso de obtención de un acuerdo entre sujetos lingüística e interactivamente competentes» ${ }^{16}$.

Partiendo del vínculo que nace de los actos de habla, Habermas sostiene que en toda emisión comunicativa el hablante plantea cuatro pretensiones de validez, que son universales, frente a las que el oyente ha de tomar postura con un sí o con un no. En el caso de que el oyente reconozca las pretensiones, se habrá logrado el entendimiento o acuerdo y eso servirá para coordinar sus planes de acción. Pero en el caso de que la postura sea un «no» a la pretensión, se puede poner fin al acto de habla — que habrá fracasado-, o bien se podrá exigir el desempeño discursivo de su pretensión. De ahí nace el compromiso de argumentar siempre nuestras opiniones. Es esa posibilidad de «demostrar» una pretensión de validez la forma que Habermas tiene de caracterizar la racionalidad: ésta se traslada a un común «dar razones» de nuestros propios actos de habla. El modelo de las pretensiones de validez está tomado, por cierto, de la práctica judicial: según la estructura de la argumentación jurídica, $A$, un hablante, sostiene que puede, llegado el caso, justificar la oferta comunicativa que ha realizado a B.

Las pretensiones de validez se presentan, de ese modo, como susceptibles de comprobación intersubjetiva ${ }^{17}$. Y aunque en todo acto de habla se plantean simultáneamente las tres pretensiones de validez — que en su conjunto recogen todo el espectro del acto de habla-, su tematización discursiva no puede ser conjunta por razones obvias: en todos los casos se presenta como dominante una de ellas ${ }^{18}$. En función de las referencias presentes en todo acto de habla — realidad exterior, sociedad y mundo interior- y de los diferentes actos que existen, Habermas considera que las pretensiones de validez son tres: es posible distinguir los actos de habla que tienen como finalidad decir algo de una realidad objetivada y que presuponen una pretensión de verdad (actos de habla constatativos), de aquellos otros que se asocian con manifestaciones normativas y que implican una pretensión de rectitud, como ocurre en el ámbito jurídico y moral

${ }^{15}$ Cfr. J. Habermas, Teoría de la acción comunicativa, op. cit., vol. I, p. 424.

${ }^{16}$ Ibid., p. 368.

17 Ibid., p. 124

${ }^{18}$ Cfr. J. Habermas, Teoría de la acción comunicativa. Complementos y estudios previos, op. cit., p. 176. Asimismo, vid. Teoría de la acción comunicativa, op. cit., vol. I, p. 365. 
(actos de habla normativos), y, por último, aquellos actos de habla que consisten en una manifestación expresiva de la interioridad y que implican una pretensión de veracidad (actos de habla expresivos) ${ }^{19}$.

Las pretensiones universales son garantías de la racionalidad del acto de habla, de cualquiera que sea, también los normativos, y en principio su tematización discursiva sólo se produce cuando el consenso o la suposición de su validez se ha roto, es decir, cuando el oyente exige al hablante que explique y justifique su comunicación. Desde un punto de vista epistemológico y metodológico, la pragmática aspira a servir de apoyo a una Teoría de la Sociedad. De un lado, sirve para ampliar el horizonte de una racionalidad manipulada sistémica, funcional e instrumentalmente; como indicábamos, es posible ensayar gracias a ella una teoría de la racionalidad que sirva de base a una teoría social amplia construida sobre los procesos de comunicación y de entendimiento.

El Derecho, si aspira a convertirse en discurso científico, se habrá de acomodar también a las peculiares exigencias de las ciencias reconstructivas y aplicar a su propio ámbito disciplinar los criterios empíricos de las mismas. Por una parte, ha de vincularse explícitamente al modelo de razón descubierta en la pragmática del habla, eliminando los residuos trascendentales y descubriendo los núcleos de la razón mediante el análisis reconstructivo de los actos de habla normativos ${ }^{20}$. Esto por lo que se refiere a los requisitos epistemológicos. Por otro lado, la pragmática ofrece el apoyo seguro de la ciencia, ya que se basa en reconstrucciones hipotéticas y, por tanto, falsables, como requiere una conciencia metodológica postempirista. Lo cual no es obstáculo para reconocer la incondicionalidad de todo saber normativo, ya que las reconstrucciones ofrecen un punto de vista contrafáctico que permite criticar —y, llegado el caso, enderezar o corregir- su derivación fáctica y empírica.

Razón, ciencia e incondicionalidad normativa son, pues, los extremos sobre los que pivota la propuesta habermasiana y sobre los que, en coherencia, también habrá de asentarse una Teoría discursiva del Derecho alternativa a las existentes. Una Teoría del Derecho que intente aclarar sus presupuestos científicos ha de partir, según el pensador alemán, de los núcleos de racionalidad y de la intelección de las competencias que laten en las prácticas sociales, en particular de las que han configurado la conceptualización

${ }^{19}$ Cfr. J. Habermas, Teoría de la acción comunicativa. Complementos y estudios previos, op. cit., pp. 75 y 98 .

20 Cfr. J. Habermas, Pensamiento postmetafísico, Madrid, 1990, p. 53. 
moderna de lo jurídico, ya que es en la modernidad, a juicio de Habermas, cuando se establece la conexión entre discurso racional y forma jurídica ${ }^{21}$. Si esto fuera así, la investigación sobre el Derecho habría de partir de su relación con los procesos democráticos de aprobación de las normas ${ }^{22}$.

\section{LA DUALIDAD INMANENTE DE LA TEORÍA DISCURSIVA DEL DERECHO}

Si tuviéramos que caracterizar la Teoría discursiva del Derecho de alguna manera no dudaríamos en afirmar que se trata de una propuesta teórica integradora en la que se entrecruzan, de forma coherente y no conflictiva, diferentes perspectivas sobre el fenómeno jurídico. De acuerdo con esto, Habermas realiza un recorrido por las visiones contemporáneas sobre el Derecho. Son, en concreto, dos los campos teóricos en los que, con mayor o menor fortuna, se ha propuesto una determinada concepción del Derecho, dos campos antagónicos que revitalizan la ininterrumpida polémica entre positivismo y iusnaturalismo: a saber, la sociología del Derecho y la filosofía moral ${ }^{23}$. La sociología, deudora de una visión objetivante que considera las normas jurídicas como fenómenos susceptibles de explicación descriptiva y autónoma, sucumbe a los cantos de sirena de un cientificismo encerrado en las estrecheces de una racionalidad sistémica. La filosofía moral, por su parte, acentúa las referencias deónticas de las prescripciones, pero lo hace a costa de su facticidad, excluyendo la coherencia con las exigencias científicas de hoy. En ninguno de estos dos casos, sin embargo, se logra comprender en su totalidad el Derecho: si la sociología se mantiene en el restringido ámbito de lo empírico, la teoría de la justicia, por su parte, se automargina en el campo moral ${ }^{24}$.

${ }^{21}$ Cfr. J. Habermas, Teoría de la acción comunicativa, op. cit., vol. II, pp. 119 ss. En la modernidad se produce lo que Habermas denomina «fluidificación lingüística» de los lazos sociales, en la medida en que las cosmovisiones aglutinantes son sometidas a crítica. De ahí la relevancia de su primera investigación sobre el origen de la esfera pública moderna, ya que en ella queda liberada la potencialidad emancipadora de la praxis comunicativa.

${ }_{22}$ Puede resultar simplista esta visión de Habermas, porque no es verosímil que la racionalidad jurídica nazca exclusivamente en la modernidad. También es cuestionable, al menos, la tesis que vincula razón normativa y aprobación democrática. Sin embargo, al ser éstas cuestiones sustantivas, su análisis excede el objeto de este trabajo.

${ }^{23}$ Habermas no es especialista en filosofía jurídica, pero atina al advertir las dos tendencias del postpositivismo, como puede verse en C. FARALLI, La filosofía del Derecho contemporánea, op. cit., p. 16.

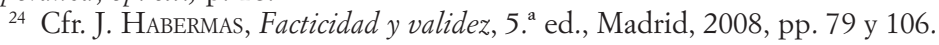


Desde la sociología, Habermas toma el modelo de las propuestas sistémicas de Luhmann, con quien, por cierto, ha mantenido fructíferas discusiones teóricas ${ }^{25}$. Luhmann se refiere al Derecho sólo desde la perspectiva externa, concibiéndolo como un sistema autopoiético y autodiferenciador ${ }^{26}$. Desde el prisma de la teoría de sistemas, el Derecho aparece como un medio de comunicación tautológicamente referido al propio sistema Derecho, encargado funcionalmente de estabilizar expectativas normativas. Gracias a estas intuiciones, Luhmann consigue fundamentar la autonomía sistémica del ámbito jurídico, lo que denomina «clausura operativa del sistema», y esquiva cualquier ponderación cualitativa de su validez ${ }^{27}$. Para Habermas es precisamente éste el error: mantenerse atado a lo sistémico, sin poder captar la normatividad incondicional, la validez, que acompaña a las normas jurídicas y sin poder acercarse a la problemática que la obediencia y el seguimiento de las normas provoca en los sujetos. La macrosociología sistémica concibe el Derecho como un subsistema más entre otros, frente a los cuales desarrolla tareas de diferenciación que lo autonomizan. Primar en exceso la autonomía impide no sólo la regulación jurídica de otros subsistemas por mor de una decisión metodológica y como consecuencia del uso de diferentes códigos, sino la obliteración de la temática de la legitimidad ${ }^{28}$. Por otro lado, en relación con los aspectos subjetivos de la obediencia a las normas, Luhmann propone una explicación conductista. En definitiva, la sociología jurídica de carácter sistémico produce la desnaturalización del Derecho y reconduce los problemas normativos de la teoría y el momento de validez incondicional de los preceptos jurídicos a su vigencia fáctica o, lo que es lo mismo, a su propia positividad ${ }^{29}$. Se pierde así la conexión del Derecho con otros componentes de la sociedad y se anula al enlace con los discursos prácticos y con las pretensiones de validez referidas a la corrección normativa.

Fue precisamente la pérdida de relevancia moral del Derecho lo que, entre otras cosas, favoreció el desarrollo de una gran parte de la filosofía

${ }^{25}$ Puede verse un resumen importante de los puntos principales de la controversia en N. LuHMANn y J. HABERMAS, Teoria della società o tecnologia sociale: che cosa offre la ricerca del sistema sociale?, Milán, 1983.

${ }^{26}$ Cfr. N. Luhmann, El derecho de la sociedad, México, 2005, pp. 67-69.

27 Ibid., p. 155.

${ }^{28}$ No es de extrañar que, para Luhmann, la propuesta jurídica de Habermas sea más bien una «ficción» que se sustenta sobre la idealización de los ausentes. Vid. N. LuHMANN, op. cit., p. 156.

${ }^{29}$ Cfr. J. Habermas, Facticidad y validez, op. cit., pp. 113-115. Ya señaló lo mismo, con carácter general, en Teoría de la acción comunicativa. Complementos y estudios previos, op. cit., p. 379. 
moral, en la que el movimiento de rehabilitación de la filosofía práctica, sobre todo en Alemania, fue paradigmático. Con independencia de que las clasificaciones son una exigencia importante en la investigación científica, es preciso reconocer que Habermas se refiere a una línea de pensamiento moral de carácter socializante. Así, por ejemplo, el representante con el que dialoga es John Rawls. En la obra de este último se superpone la reivindicación de la filosofía moral con ramificaciones en la esfera jurídica. A Theory of Justice, que tuvo un resonante eco, es la obra que Habermas toma como modelo de este movimiento, empeñado en apuntar las referencias axiológicas de las normas jurídicas. El norteamericano desarrolló, en efecto, una concepción en la que la justicia era considerada la virtud fundamental del orden social, sin llegar a traspasar los márgenes de la filosofía moral $^{30}$. Desde el punto de vista de la Teoría del Derecho se debe considerar insuficiente e irreal la preferencia del estatuto normativo de la teoría de la justicia. Analíticamente, Habermas ha diferenciado a este respecto las cuestiones morales y las jurídicas. Las primeras, explica, reclaman una pretensión de validez universal, mientras que la validez normativa del Derecho se refiere siempre al marco de una determinada comunidad jurídica, por lo que sus pretensiones son generales, pero no universalizables - aunque algunas normas se postulen como universalizables-. Además, el punto de vista moral de Rawls sólo puede percibir las normas bajo el prisma de su legitimidad y validez deóntica, sin entrar en detalles importantes de la vida jurídica como la vigencia social de las normas, su institucionalización o la dialéctica de su eficacia ${ }^{31}$. Su punto de vista es, pues, como el de Luhmann, también reduccionista.

En resumidas cuentas, puede decirse que a un planteamiento le falta lo que al otro le sobra. Si la filosofía moral pierde contacto con la dinámica social por privilegiar la validez deóntica, situándose en la abstracción de situaciones ideales, la perspectiva sociologista obvia las referencias axiológicas. Está claro que lo que no es científico en ningún caso es «empecinarse en ninguna orientación ligada a una sola disciplina» ${ }^{32}$, como expresamente se nos advierte. Al científico social, que quiere proponer una alternativa teórica basada en un paradigma novedoso y omnicomprensivo, se le impone la necesidad de ensayar un tertium gens que, metodológica y sustancialmente, recoja la divergencia y alivie la tensión entre las teorías sociológi-

${ }^{30}$ Cfr. J. Rawls, A theory of Justice, Cambridge, 2005, pp. 3 y 46. Los traspasó, proponiendo un modelo de razón pública, en Liberalismo político, México, 1995.

${ }_{31}$ Cfr. J. Habermas, Facticidad y validez, op. cit., p. 129.

32 Ibid., p. 68. 
cas y las teorías morales. Esa divergencia está enunciada, justamente, en el título de la obra que se ocupa sobre el Derecho y que hace referencia a la tensión entre la facticidad de las normas, o su eficacia social, y su validez incondicionada. Una teoría social que busca ser completa y definitiva no puede desconocer, en fin, la relevancia teórica de esta polaridad ${ }^{33}$.

Puede decirse, pues, que la Teoría discursiva el Derecho, para ser coherente, ha de procurar estabilizar esas dos visiones que manifiestan una tensión inmanente del fenómeno jurídico, y debe intentar combinar el estudio de las normas desde el punto de vista de la justicia con el de su vigencia fáctica. Se entiende, entonces, que, con independencia de otros problemas de los discursos jurídicos, esta Teoría del Derecho se nos antoja una buena alternativa a los planteamientos actuales. De acuerdo con el paradigma que hemos mencionado, Habermas reconstruye el Derecho a partir de lo real existente operando con idealizaciones. El punto de inicio de su Teoría del Derecho se encuentra en «las formas de comunicación articuladas en términos de Estado de Derecho, en las que se desarrollan la formación de la voluntad política, la producción legislativa y la práctica de decisiones judiciales». Por medio de su reconstrucción se habrá «obtenido a la vez un estándar crítico con el que poder juzgar las prácticas» ${ }^{34}$.

\section{DIMENSIONES SOCIOLÓGICAS Y FILOSÓFICAS. EL DERECHO MODERNO COMO GARANTÍA DEL ORDEN SOCIAL}

Una Teoría deliberativa del Derecho requiere pues combinar en un proyecto teórico común la dimensión sociológica e institucional del fenómeno jurídico con la perspectiva axiológico-moral de las normas. Para advertir de qué forma Habermas pone fin a esa controversia disciplinaria y metodológica es menester referirse a una de las primeras dimensiones en las que se pone de manifiesto la dialéctica entre facticidad y validez. La peculiaridad del planteamiento habermasiano radica, precisamente, en ver la conexión de estos problemas de fundamentación con la constitución de una Teoría del Derecho que, sin menospreciar las exigencias científicas, tampoco orilla la incondicionalidad de la validez normativa. Sólo demostrando que la teoría deliberativa responde con éxito a pacificar esa tensión

33 Ibid., pp. 130 y 147.

${ }^{34}$ Ibid., p. 67. 
inmanente en la Teoría de la Sociedad podrá postular su análisis del Derecho como una vía alternativa a las visiones sociologistas y moralistas.

La tensión entre la facticidad y la validez descubierta en el seno del Derecho, esa tensión inmanente, nos permite ahora conectar desde un punto de vista metodológico la Teoría del Derecho con los postulados fundamentales de la Teoría de la Sociedad habermasiana, ya que en el Derecho se revela internamente la estructura dialéctica de los procesos comunicativos que configuraban la potencialidad científica de la pragmática universal, esto es, que avalaban la perspectiva normativa y descriptiva de las únicas ciencias viables hoy, las reconstructivas ${ }^{35}$. En este sentido, Habermas, siguiendo la estela de la Escuela de Frankfurt, observa la exigencia recíproca entre el sistema social, las necesidades y las condiciones de la reproducción social, y el anhelo de razón que apunta al ideal de una vida social libre y autoconsciente. Esa contienda entre lo que es y lo que debe ser, que Adorno no pudo conceptuar científicamente por medio de la negatividad de su proyecto dialéctico, se refleja en la estructura del habla - y, por tanto, también en la del Derecho-, cuyo reflejo permite que las prácticas comunicativas de los hablantes adquieran el estatuto fundamental de toda la Teoría de la Sociedad. Veamos cómo sucede esto. Los procesos de comunicación se sustentan sobre idealizaciones; los sujetos que entablan pretensiones de validez apelan a la fuerza incondicionada de la razón en el medio lingüístico que regula sus interacciones contingentes. El espectro teórico de la pragmática universal aclara la dimensión contrafáctica de las pretensiones de validez — ya sea de la verdad, de la corrección normativa o de la sinceridad, en sus discursos específicos-, que sólo pueden plantearse y desempeñarse discursivamente en el contexto u horizonte común del mundo de la vida social, que actúa como trasfondo posibilitante de la interacción.

Desde el punto de vista de la teoría social, lo dicho hace posible que las interacciones apoyen la integración social, ya que están basadas en la fuerza trascendente del compromiso con la racionalidad que todo hablante adquiere al emitir un acto de habla. El lenguaje posibilita la coordinación de los plexos de acción y explica, en última instancia, el orden social. Pero toda acción y, por tanto, todo acto de habla subyacente, remite a un núcleo de racionalidad discursiva; la razón invade, por decirlo así, el propio mundo social y, sin cerrar la posibilidad de las refutaciones ni de iniciar

${ }^{35}$ Habermas entiende que las reconstrucciones son la opción más aceptable en las ciencias sociales, aunque también es consciente de sus insuficiencias y trata de solventarlas. Cfr. Conciencia moral y acción comunicativa, op. cit., p. 176. 
en su caso discursos de corroboración, es el nexo a partir del cual puede edificarse una Teoría de la Sociedad empírica, científica y normativa.

La pragmática universal permite, de ese modo, la intelección de la dialéctica metodológica de la facticidad y la validez, tensión que tiene alcance constituyente en el proyecto habermasiano y, en particular, en su concepción jurídica. La validez de un acto de habla viene determinada por la orientación al entendimiento, definido en términos de incondicionalidad normativa, de las acciones sociales. Entenderse, como repite insistentemente Habermas, es orientarse para lograr acuerdos válidos y, por tanto, racionales $^{36}$. En sus interacciones los sujetos asumen compromisos que apuntan a esferas que están más allá de todo contexto, pero, al mismo tiempo, las acciones sociales no pueden obviar el problema de la aceptación de sus presupuestos en la práctica, en la realidad cotidiana de un mundo de la vida social determinado: en el aquí y ahora se acredita su facticidad ${ }^{37}$.

¿Cómo se traslada esa problemática entre la facticidad y la validez al ámbito jurídico? El Derecho constituye un importante factor en la reflexión social justamente porque en él se manifiesta internamente la problemática constituyente de la pragmática universal y porque, desde un punto de vista externo, el Derecho es un elemento imprescindible para el orden social. En este último sentido, el pensador alemán trata de comprender en qué medida las normas jurídicas son relevantes para alcanzar la estabilidad social contando con el juego de sus presupuestos idealizadores y su vigencia. El Derecho coordina y orienta diferentes planes de acción, estabilizando las diversas pretensiones de los agentes que, de otra forma, romperían anárquicamente el mínimo de orden imprescindible para la conservación de la sociedad.

Esta precisión es decisiva en la medida en que muchos desacuerdos y conflictos de acción se evitan, según Habermas, de forma espontánea, gracias al consenso del mundo de la vida social, trasfondo común a toda interacción y alma nutricia de lealtades y visiones compartidas implícitamente por todos los individuos. Pero, pese a que el mundo de la vida social es la garantía última de la vida social pacífica — como tal no puede ser sometido a refutaciones globales ni a críticas totalizadoras-, la ruptura de la incuestionabilidad de los marcos culturales, propia de la modernidad, desafía esas supuestas fidelidades y en las sociedades modernas se producen conflictos que ya no pueden solventarse recurriendo a una cosmovisión com-

${ }^{36}$ Cfr. J. Habermas, Teoría de la acción comunicativa, op. cit., vol. I, p. 500.
${ }^{37}$ Cfr. J. Habermas, Facticidad y validez, op. cit., p. 82. 
partida. El Derecho moderno aparece entonces para suplir las deficiencias de un orden social que resulta del proceso de racionalización. Para ver realmente cómo sucede esto es necesario aclarar algunos aspectos de la Teoría de la Evolución Social de la que parte Habermas.

Desde un punto de vista evolutivo, en las sociedades premodernas la visión omnicomprensiva de las formas culturales aseguraba que la matriz consensual de la sociedad, si bien de forma implícita, mantuviera en latencia el conflicto entre la facticidad y la validez. De hecho, la explicitación de esa dialéctica es un fenómeno que Habermas considera típicamente moderno: con el nacimiento de la modernidad se fractura la uniformidad de la cultura y la sociedad. La diferenciación de los respectivos órdenes sistémicos especializados, que actúan como factores desequilibrantes de la unidad cultural, provocan crisis sociales. Y las sociedades no tienen más remedio que enfrentarse a las contingencias que desafían sus presupuestos, buscando remedios que alivien la tensión y pacifiquen los conflictos con normas de carácter vinculante y validez incondicionada ${ }^{38}$.

El Derecho, desde este punto de vista evolutivo, es el modo en que las sociedades complejas pueden seguir manteniendo un mínimo de orden y de estabilidad mientras, al mismo tiempo, se amplían las redes comunicativas y se multiplican potencialmente los conflictos. Y tiene que ser el Derecho, porque otros recursos resultarían anacrónicos. No puede, por ejemplo, reivindicarse sin más una vuelta a ese estado social anterior a las conquistas modernas, como postulan los antimodernos. Tampoco puede renunciarse a los logros científicos y morales de la modernidad, ya que las estructuras normativas y cognoscitivas alcanzan estadios de desarrollo irreversibles. La especialización funcional, la constitución de esferas de saber reflexivo y diferenciado, la formalización de la conciencia moral normativa, son fenómenos, entre otros, que no se pueden ignorar y que se suceden de forma necesaria según una lógica evolutiva.

Pero el hecho es que la libre fluctualización de la acción comunicativa amplía el espacio de contingencia en el que los hablantes han de coordinar sus acciones con acuerdos y consensos. Ese espacio manifiesta que la integración social, al basarse en la comunicación, ya no se encuentra asegurada, o no lo está en toda su dimensión, por el haz de tradiciones no tematizables que constituía el trasfondo incuestionable del mundo de la vida social. La integración social pasa entonces a depender en un mayor grado del entendimiento libre de los hablantes en las interacciones cotidianas,

${ }^{38}$ Ibid., p. 86. 
porque en las sociedades modernas y contemporáneas proliferan los posicionamientos críticos, las denuncias ideológicas y las refutaciones del acervo cultural de la sociedad. Pero si, de un lado, la validez incondicionada del mundo de la vida social se reduce inexorablemente ${ }^{39}$, por otro, la evolución sistémica y la especialización funcional crea subsistemas autónomos sometidos a una lógica fáctica que amenazan la integridad del mundo de la vida social con sus embates colonizadores ${ }^{40}$.

A partir de estas consideraciones, es fácil comprender el alcance que adquiere el Derecho como instrumento para resolver problemas de integración y coordinación de las acciones en una Teoría de la Sociedad constituida a dos bandas, como mundo de la vida social y sistema. La tensión entre la facticidad y la validez que aparece en el ámbito gnoseológico de la pragmática se traslada al ámbito sustantivo de la Teoría de la Sociedad, se manifiesta en la específica dualidad disciplinaria que Habermas aprecia en el seno de la Teoría del Derecho - a la que nos hemos referido en el epígrafe anterior- y busca una solución práctica en la Teoría deliberativa del Derecho. Porque, en efecto, en las sociedades modernas y contemporáneas, en las que surge el problema de conciliar la estabilidad de un determinado orden con la posibilidad de que los actores se conduzcan no sólo con acciones orientadas al entendimiento, sino conforme a la estructura de una racionalidad estratégica que obvia los entendimientos discursivos, el Derecho facilita el aseguramiento del orden y la consecución de una mínima integración social ${ }^{41}$. La regulación normativa de las acciones en la modélica forma que adquiere con la institucionalización moderna del Derecho flexibiliza una tensión que se extiende a toda Teoría de la Sociedad, desde el plano epistemológico, pasando por el metodológico y el sustantivo.

Pero ¿en qué medida puede decirse que el Derecho alivia o descarga la dialéctica entre facticidad y validez? En primer lugar, el Derecho elimina la tensión entre normatividad y facticidad porque las normas jurídicas coligan los límites de las proyecciones estratégicas de los individuos con la apelación a pretensiones de validez normativas, y siempre racionales, que exigen el acuerdo y el reconocimiento intersubjetivo. En segundo término, la tensión entre facticidad y validez se reproduce en el seno de la propia juridicidad. En ella se aúna la necesidad de la imposición del derecho de forma coactiva por parte del Estado - la única manera de asegurar el

\footnotetext{
${ }^{39}$ Cfr. J. Habermas, Facticidad y validez, op. cit., p. 87.

${ }^{40}$ Cfr. J. Habermas, Teoría de la acción comunicativa, op. cit., vol. I, p. 486.

${ }^{41}$ Cfr. J. Habermas, Facticidad y validez, op. cit., p. 84.
} 
cumplimiento de ciertas normas a pesar del disenso o la oposición irracional- con la fuerza normativa que surge de un derecho aprobado siguiendo los procedimientos discursivos y racionales que acreditan su legitimi$\mathrm{dad}^{42}$. Este segundo aspecto es importante porque permite considerar cómo el Derecho moderno aúna las diferentes perspectivas de la teoría de la acción: en efecto, los individuos pueden guiarse bien por miedo a la sanción, bien atendiendo a la legitimidad de las normas válidas, sin que en ningún caso se produzca riesgo para la estabilidad social.

\section{EL DERECHO, ENTRE LA POLÍTICA Y LA MORAL}

El interés de Habermas por el Derecho procede, como hemos tratado de indicar, de exigencias que se plantean en el seno de su Teoría de la Sociedad. En este sentido, el prisma desde el cual se acerca al Derecho es eminentemente sociológico. Ahora bien, si se tiene en cuenta lo que hemos mencionado al principio, es decir, que la ciencia social es el lugar idóneo para debatir las cuestiones acerca de la racionalidad, se puede entender entonces que este planteamiento no sólo no es reduccionista, sino que es el único posible en esta etapa del desarrollo científico. Se supera de esa forma la visión más reductiva de la sociología del Derecho, puesto que si bien es cierto que el Derecho actúa en la Teoría de la Sociedad habermasiana como un mecanismo que descarga de tensión la red comunicativa del mundo de la vida social, mermado y expuesto a distorsiones en las sociedades de hoy, no por ello está exento de presupuestos de validez ${ }^{43}$.

La dualidad del sistema - mundo de la vida, facticidad y validez, ciencia empírica o teoría normativa- reaparece en su consideración del Derecho como un elemento que sirve de bisagra entre el mundo de la vida y el sistema social, posibilitando su comunicación y, sobre todo, su equilibrio. La dualidad jurídica está representada también en la tensión entre dos polos, el moral y el político. El Derecho se manifiesta sustantivamente como un medio de comunicación, un código binario, que solventa las dificultades del lenguaje cotidiano y hace posible las relaciones estructurales de dichos ámbitos. Mientras que el habla y el lenguaje ordinario no son eficaces para conseguir el equilibrio entre las tendencias objetivas del sistema y las preferencias axiológico-normativas del mundo de la vida social,
42 Ibid., p. 91.
${ }^{43}$ Ibid., p. 100. 
porque estos componentes utilizan códigos diferentes, el Derecho actúa como un transformador que «asegura que la red sociointegradora no se rompa» a lo largo del espectro social, permitiendo una comunicación recíprocas de exigencias ${ }^{44}$. Ahora bien, no hay que olvidar que al ser un medio de comunicación situado en los intersticios de los ámbitos constituyentes de la sociedad, el Derecho como instrumento de integración corre el riesgo de ser manipulado por el sistema y servir a la colonización ideológica y reduccionista del mundo de la vida social ${ }^{45}$.

Como factor de intermediación, la Teoría discursiva del Derecho tiene que quedar asociada con los recursos que favorecen también la integración social. Estas relaciones ambiguas y complejas de lo jurídico a lo largo del espectro social deciden, en última instancia, su manejabilidad. Puede servir para corregir las fallas del mercado o puede enderezar las incorrecciones del poder administrativo y burocrático, remitiendo a los procesos comunicativos y discursivos sobre los que se funda su legitimidad. En ambos casos, el Derecho aparecería como un factor fundamental en la emancipación de las sociedades y en el desarrollo normativo de las mismas. Pero al situarse en esa zona intermedia, también la forma jurídica puede ser adquirida por mensajes sistémicos que se independizan de los contextos comunicativos y establecen el cortocircuito entre las exigencias del mundo de la vida social y el sistema. En este último caso, al apoyar la expansión de las prescripciones sistémicas y privilegiar su racionalidad unilateral, el Derecho se convierte en un factor determinante de la pauperización y aniquilación paulatina de los contextos comunicativos.

Precisamente, la imbricación con el momento de validez permite evitar los riesgos de esa sistematización abusiva del fenómeno jurídico. Es en este punto en el que la perspectiva de Habermas supera el planteamiento descriptivista de la sociología jurídica y se abre al componente moral de las normas. Porque la problemática en torno a la legitimidad de las normas conduce inexorablemente al ámbito de su producción. De este modo, Habermas puede decir que «el proceso de producción de normas constituye, por tanto, en el sistema jurídico el auténtico lugar de la integración social» ${ }^{46} \mathrm{y}$ conectar de forma interna la génesis del Estado de Derecho con la fundamentación moderna de la democracia.

${ }^{44}$ Ibid., pp. 120 y 143.

${ }^{45}$ Así lo hemos tratado de poner de manifiesto en J. M. Carabante Muntada, «El Derecho: ¿objeto tecnificado o medio de tecnificación? La dualidad del proceso de racionalización jurídica en la obra J. Habermas», Persona y Derecho, núm. 62, 2010.

${ }^{46}$ Cfr. J. Habermas, Facticidad y validez, op. cit., p. 94. 
La derivación procedimentalista del Derecho no significa, en cualquier caso, su indiferenciación con respecto a los procedimientos morales, pero sí supone admitir que la acreditación formal de los procedimientos de creación de normas jurídicas remiten a la fundamentación moral de principios universalistas ${ }^{47}$. Además de ámbitos de aplicación diferentes - unas normas pretenden validez universal, mientras las jurídicas se refieren a un contexto determinado-, según Habermas a los discursos morales les faltan recursos para garantizar el cumplimiento de los resultados obtenidos, de forma que califica este tipo de discurso de racionalidad procedimental perfecta e incompleta, mientras que en el Derecho cuenta con el apoyo institucional.

El Derecho, pues, tal y como Habermas lo conceptúa, se sitúa en una zona intermedia entre la moral y la política, de forma que mantiene sobre sí siempre la espada de Damocles del idealismo axiológico — sea cual sea su vertiente- y también de su instrumentación política. Pero es también el fenómeno jurídico una manifestación de esa racionalidad que Habermas descubrió inserta en los discursos. «El derecho positivo - explica Habermas en el epílogo a la cuarta edición de Facticidad y validez- no puede obtener ya su legitimidad de un derecho moral que quedase por encima de él [...] sólo pueden pretender legitimidad aquellas regulaciones normativas y formas de acción a las que todos los posibles afectados pudiesen prestar su asentimiento como participantes en discursos racionales» ${ }^{48}$. Se trata de aplicar, en definitiva, el Principio Discursivo (PD) que exige el nivel de razón de signo discursivo y reconducirlo positivamente al interior del Estado democrático de Derecho ${ }^{49}$.

La divergencia del principio discursivo en principio de universalización moral y principio democrático del Derecho revela las desemejanzas entre el fenómeno jurídico y la moralidad. Los discursos morales son universales, como hemos indicado, mientras que los discursos jurídicos se circunscriben a una determinada comunidad constituida jurídicamente: su ámbito de validez es concreto espacial y temporalmente. El principio de universalización de la moral es interno al juego de la argumentación; en cambio,

47 Ibid., p. 556.

48 Cfr. J. Habermas, Facticidad y validez, op. cit., p. 656.

49 Es importante señalar que esto es lo que diferencia la propuesta de Habermas de otras teorías discursivas del Derecho que, aun inspirándose en su propia obra, terminan subordinando el Derecho a la moral y, por tanto, no reconocen la bifurcación de un mismo principio discursivo en principio moral y principio democrático. Cfr. Facticidad y validez, op. cit., pp. 307 ss. 
el principio democrático resulta externo porque se establece en la efectiva institucionalización de los discursos y depende de la participación real del ciudadano en la producción de las normas jurídicas ${ }^{50}$.

Por otro lado, también la regulación de ambos discursos evidencia asimetrías. En el discurso moral exclusivamente entran en consideración razones de justicia universal: en este sentido, se sitúan en exclusiva en lo que Habermas llama «uso moral de la razón práctica». El ámbito de los discursos jurídicos recoge el espectro de la racionalidad práctica en toda su extensión: caben, en concreto, razones morales, pero también pragmáticas o éticas, y esto se explica, precisamente, porque el Derecho es una categoría de mediación o integración social que facilita la comunicación entre sistema y mundo de la vida. Por ello mismo, el Derecho no se agota en la tarea de regular conflictos, como la moral ${ }^{51}$. Las normas jurídicas son medios, mientras que las morales son fines en sí. También hay una diferencia de grado de especificidad: los discursos morales se refieren a toda norma, si bien destacan su base moral, siempre que aquéllas sean universalizables; en el discurso jurídico, lo inespecífico son los discursos y las razones a aducir por los participantes, pero sólo pueden referirse a normas de carácter formalmente jurídico que regulan la acción típica y externa de los ciudadanos.

La Teoría discursiva del Derecho se presenta de nuevo como alternativa al afirmar el entrelazamiento inmanente entre moral y Derecho. La fuente discursiva y comunicativa de la que ambos nacen sirve en los dos casos para solventar la incondicionalidad de las normas y afirmar, en el caso del Derecho, su legitimidad. La concepción procedimentalista de las normas que plantea Habermas significa que la moral emigra al interior del Derecho, por emplear la expresión del pensador alemán, y se entromete en el espacio discursivo sin agotar su sustancia en Derecho positivo ${ }^{52}$. A través del proceso de producción legislativa, regulado discursivamente, penetra en el ordenamiento jurídico la razón moral. En este sentido, moral y Derecho, como sistemas normativos complementarios, se vigilan y controlan recíprocamente, sin llegar nunca a confundirse.

\footnotetext{
50 J. Habermas, Facticidad y validez, op. cit., pp. 176 y 658-659.

${ }^{51}$ Ibid., p. 558.

52 Ibid., p. 559.
} 


\section{CONCLUSIONES}

Hemos perfilado en las páginas anteriores los principios y aspectos básicos de la Teoría discursiva del Derecho. La intención era demostrar que este proyecto teórico permite recuperar y actualizar una nueva Teoría del Derecho que cuenta con una acreditación metodológica suficiente. La racionalidad discursiva es un modelo al que nuestra disciplina no puede dejar de prestar atención, aunque la decantación cientificista de la misma haya generalizado, como hemos indicado en la introducción, una alergia a los cuestiones de fundamentación. Pese a las indudables críticas a las que puede someterse el planteamiento habermasiano, lo que tratábamos de poner de manifiesto era su potencialidad ${ }^{53}$. La Teoría discursiva del Derecho posee un estatuto epistemológico y metodológico que justifican su inclusión en los planes de estudio, sin restar importancia al análisis de las normas - típico de la Ciencia del Derecho- ni a los aspectos normativos implicados en el fenómeno jurídico — recogiendo, pues, la estela del Derecho natural, que conformaba una asignatura introductoria y fundamental en los planes de Derecho, o también ahora de la Filosofía del Derecho-. Ya la propia tensión inmanente al Derecho, que Habermas engloba en la expresión Faktizität und Geltung, manifiesta la específica dualidad disciplinaria que, aunque en ocasiones complica la investigación, debería ser a estas alturas incuestionable.

Asimismo, a nadie se le escapa que la propuesta de Habermas es sugerente y que permite abrir de nuevo el debate sobre los principales puntos de la Teoría del Derecho. Se puede echar en falta, ciertamente, concreción en algunas discusiones, pero precisamente éstas, por constituir asuntos más especializados, opacarían la visión global desde la que Habermas contempla el Derecho. No obstante, hay que señalar que lo que Habermas propone son los presupuestos científicos de una Teoría del Derecho; hay que matizar algunas cosas y, sobre todo, el trabajo que se desarrolle en esa línea habrá de responder a las cuestiones de detalle. El desarrollo de la temática propia de la Teoría del Derecho corresponde hacerlo a quienes nos dedicamos a la tarea docente e investigadora en este campo.

A modo de conclusión puede decirse que si se tiene en cuenta que el discurso filosófico-moral sobre la justicia no ha reparado con la aten-

${ }^{53}$ Un análisis sobre las implicaciones de la Teoría discursiva del Derecho y su relación con la teoría deliberativa de la democracia se encuentra en R. v. SCHOMBERG y K. BAYNES (eds.), Discourse and democracy: essays on Hebermas's facts and norms, Albany, 2002, pp. 26 ss. 
ción debida sobre la dimensión sistémica desde la que es posible estudiar el Derecho y, por su parte, en las aproximaciones descriptivas predomina una mirada objetivante, la única alternativa viable hoy es la que ofrece la teoría discursiva, ya que es la base de la racionalidad discursiva y procedimental, que también anida en la producción moderna de las normas jurídicas, la única dimensión que, como indica Habermas, «puede asegurar al Derecho positivo un momento de incondicionalidad y una estructura sustraída a ataques y manipulaciones contingentes ${ }^{54}$. Con esa remisión a la incondicionalidad y normatividad a la que aspiran unas normas elaboradas en procesos contingentes se asegura también la potencialidad crítica de la aproximación habermasiana al fenómeno jurídico.

${ }^{54}$ Ibid., p. 586. 